\title{
Sintering of nano crystalline $\alpha$ silicon carbide by doping with boron carbide
}

\author{
M S DATTA, A K BANDYOPADHYAY ${ }^{\dagger}$ and B CHAUDHURI* \\ Department of Metallurgical Engineering, Jadavpur University, Kolkata 700 032, India \\ ${ }^{\dagger}$ College of Ceramic Technology, Kolkata 700 010, India
}

MS received 18 August 2001; revised 8 February 2002

\begin{abstract}
Sinterable nano silicon carbide powders of mean particle size $(37 \mathrm{~nm})$ were prepared by attrition milling and chemical processing of an acheson type alpha silicon carbide having mean particle size of $0.39 \mu \mathrm{m}$ $(390 \mathrm{~nm})$. Pressureless sintering of these powders was achieved by addition of boron carbide of $0.5 \mathrm{wt} \%$ together with carbon of $1 \mathrm{wt} \%$ at $2050{ }^{\circ} \mathrm{C}$ at vacuum ( $3 \mathrm{mbar}$ ) for $15 \mathrm{~min}$. Nearly $99 \%$ sintered density was obtained. The mechanism of sintering was studied by scanning electron microscopy and transmission electron microscopy. This study shows that the mechanism is a solid-state sintering process. Polytype transformation from $6 \mathrm{H}$ to $4 \mathrm{H}$ was observed.
\end{abstract}

Keywords. Sintering mechanism; silicon carbide; boron carbide; polytype.

\section{Introduction}

Silicon carbide has generated considerable interest in recent years as a potential material for many high temperature applications in its dense high temperature form. These materials are being proposed for use as structural materials in power generating turbines to increase their efficiency by raising the turbine gas inlet temperature to about $1400^{\circ} \mathrm{C}$. These materials are also considered for automotive gas turbines, small automotive thermal reactors, roller bearing and advanced combustion chambers applications. For these, as well as for future areas of application, it is important to have an understanding of their sintering kinetics and the fundamental mechanisms of sintering. Due to the amount of covalent bonding in silicon carbide, it is not possible to obtain high densities with pure material using a normal sintering process. The hot pressing technique with additions of small amounts of $\mathrm{B}, \mathrm{Al}, \mathrm{Ni}$ among others (Kriegesman et al 1986) is well known but is limited to the production of rather simple shapes. Hot isostatic pressing may be used for fabrication of more complicated geometries.

Pressureless sintering of silicon carbide has been reported by Prochazka (1975) who synthesized $\beta$ silicon carbide in the submicron range which was sintered after addition of $0.5 \mathrm{wt} \%$ boron and $1 \mathrm{wt} \%$ carbon in the temperature range $2050^{\circ} \sim 2150^{\circ} \mathrm{C}$ to densities of $96 \%$ in argon atmosphere.

In its pure form, $\mathrm{SiC}$ powder will not sinter to a fully dense state. By heating at the temperature range of $1900^{\circ}$

\footnotetext{
*Author for correspondence
}

$\sim 2300^{\circ} \mathrm{C}$ with pressures ranging from 100-400 MPa, Kriegesman et al (1986) were able to manufacture porefree (dense) particles of polycrystalline silicon carbides starting from green bodies of $50 \%$ green density without the use of sintering aids. In the meantime, Prochazka (1975) reported that with addition of boron and carbon to submicron size $\beta$-SiC, sintering of silicon carbide to near theoretical density was achieved. He proposed that during the firing of pure submicron powders of covalently bonded solids, densification is prevented by a hypothetically high ratio of grain-boundary to solid-vapour surface energies, i.e. $\gamma_{\mathrm{GB}} / \gamma_{\mathrm{SV}}$. In order that a pore surrounded by three grains shrinks to closure, the equilibrium dihedral angle $(\theta)$ must be $>60^{\circ}$ or $\gamma_{\mathrm{GB}} / \gamma_{\mathrm{Sv}}$ must be $<3$. The equation connecting these parameters that applies at the solidvapour interface is

$$
\gamma_{\mathrm{GB}}=2 \gamma_{\mathrm{SV}} \cos \theta / 2 \text {. }
$$

The argument was proposed by Prochazka (1975) to explain the role of boron and carbon. As $\gamma_{\mathrm{GB}}$ for $\mathrm{SiC}$ is expected to be high due to strong directionality of $\mathrm{Si}-\mathrm{C}$ bonds, $\gamma_{\mathrm{GB}} / \gamma_{\mathrm{Sv}}$ ratio is also too high and sintering is thus inhibited. He explained the role of boron and carbon as follows: (i) due to strong directionality of $\mathrm{Si}-\mathrm{C}$ bonds, $\gamma_{\mathrm{GB}}$ for $\mathrm{SiC}$ is high, therefore $\gamma_{\mathrm{GB}} / \gamma_{\mathrm{SV}}$ is also high. Boron segregates selectively along grain-boundaries decreasing $\gamma_{\mathrm{GB}}$ and consequently $\gamma_{\mathrm{GB}} / \gamma_{\mathrm{SV}}$ and (ii) since $\gamma_{\mathrm{SV}}$ for $\mathrm{SiC}$ is high, its surface has a tendency to adsorb impurities and lower $\gamma_{\mathrm{SV}}$, thus increasing $\gamma_{\mathrm{GB}} / \gamma_{\mathrm{SV}}$. Silicon and silica which lower $\gamma_{\mathrm{SV}}$ for $\mathrm{SiC}$ by this process should be removed. Carbon removes $\mathrm{SiO}_{2}$ and $\mathrm{Si}$ by forming $\mathrm{SiC}$ and $\mathrm{CO}$.

On the other hand, Lange and Gupta (1976) used mixtures containing $\beta$-SiC with different amounts of $B$ 
and $\mathrm{C}$ or $\mathrm{B}_{4} \mathrm{C}$. After its sintering their microstructural observations strongly suggested that a boron rich liquid was present during densification. From their observations, they concluded that either reaction sintering or liquid phase sintering is responsible for densification of submicron silicon carbide added with boron and carbon addition.

Reports concerning the solubility and lattice position of B in SiC are contradictory. Shaffer (1969) reported solubility at $2500^{\circ} \mathrm{C}$ of $0.1 \mathrm{wt} \%$. By contrast, a solubility of $0.5 \mathrm{wt} \%$ at $2200^{\circ} \mathrm{C}$ was determined by Murata and Smoak (1978). Lattice parameter measurements of the lattice upon incorporation of B suggests that this element substitute for $\mathrm{Si}$ or $\mathrm{C}$. A comparison by Tajima and Kingery (1982) of these data with theoretical calculations suggested that the aforementioned lattice contraction is less than what would be expected if all B atoms replaced $\mathrm{Si}$. Considerations of strain energy and bonding stability favour the incorporation at $\mathrm{C}$ and $\mathrm{Si}$ sites simultaneously. Thus boron may occupy both sites simultaneously and subsequently as a function.

Scanning transmission electron microscopy (STEM), auger electron spectroscopy (AES), wavelength-dispersive $\mathrm{X}$-ray analysis and microautoradiography studies were conducted by Hamminger et al (1983) on several $\alpha$-SiC separately doped with $\mathrm{Al}$ and $\mathrm{C}$ or $\mathrm{B}$ and $\mathrm{C}$ which showed a heterogeneous region of $\cong 200 \mu \mathrm{m}$ diameter containing $\mathrm{B}, \mathrm{O}, \mathrm{N}, \mathrm{Al}$, and/or $\mathrm{C}$ enrichments.

In this paper, we report our studies on sinterability of nano crystalline alpha silicon carbide with addition of boron carbide and carbon, its effect on microstructure and the mechanism of sintering.

\section{Experimental}

\subsection{Powder preparation and characteristics}

A commercially available acheson type alpha silicon carbide powder of grade 1000 from M/s Grindwell Norton Ltd, India, with a silicon carbide content of $98.7 \%$ and a specific surface area of $1.5 \mathrm{~m}^{2} / \mathrm{g}$ (measured by Surface

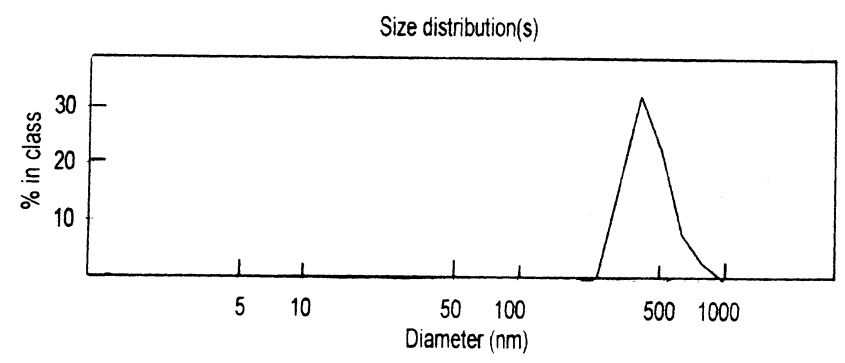

Figure 1. Particle size distribution of initial starting $\alpha$ silicon carbide powder.
Analyser, Micromeritics, USA) was used as a starting material. The initial particle size, measured in Zetasizer $1000 \mathrm{HS}$ of $\mathrm{M} / \mathrm{s}$ Malvern Instruments Ltd, UK, has a mean particle size of $0.39 \mu \mathrm{m}$. The particle size distribution has been given in figure 1. After milling in an attrition mill (Model PRIS of M/s Metisch Feinmath Technik GmbH, Germany) with special active agent for oxygen removal for $12 \mathrm{~h}$ at a $\mathrm{pH}$ of 9 , the iron wear was removed by treating it with hydrochloric acid. An excess carbon in the powder was burnt off in air at $700^{\circ} \mathrm{C}$. Since a slight oxidation of the silicon carbide powder occurred under these conditions, the powder was treated with hydrofluoric acid to remove the silica formed on the surface of the powders. The powder's characteristic is given in table 1 and the particle size distribution was measured using a particle size analyser Malvern Autosizer, 2C of $\mathrm{M} / \mathrm{s}$ Malvern Instruments Ltd, UK and is shown in figure 2 and the particles were also seen using a transmission electron microscope (JEOL TEM 400CX, Jeol, Japan) (figure 3 ). The final processed powder had a mean size of $37 \mathrm{~nm}$.

\subsection{Sintering additives}

Boron carbide from M/s Starck A, West Germany having a purity of $99.5 \%$ was used as sintering aid along with carbon. Phenolic resin from M/s Allied Resin \& Chemicals Ltd, India, was used as a source for carbon. Phenolic resin pyrolizes at high temperature with a carbon yield of $47 \%$ (Carbon content of resin was measured by firing at $700^{\circ} \mathrm{C}$ for $1 \mathrm{~h}$ in argon atmosphere).

\subsection{Sample preparation}

The milled nano crystalline silicon carbide powder and the additives were mixed under acetone and $1 \mathrm{wt} \%$ of oleic acid was added as pressing aid in solution. After drying of the slurry at $80^{\circ} \mathrm{C}$, the mixture was passed through a sieve of mesh 60 and the sieved granules were compacted isostatically at a pressure of $270 \mathrm{MPa}$ to a green density of $62 \%$.

Table 1. Powder characteristics.

\begin{tabular}{llc}
\hline Phase composition & & Mainly $\alpha 6 \mathrm{H}-\mathrm{SiC}$ \\
\hline Total carbon & $\mathrm{wt} \%$ & $30 \cdot 27 \%$ \\
Free carbon & $\mathrm{wt} \%$ & $1 \%$ \\
Oxygen & $\mathrm{wt} \%$ & $0 \cdot 33$ \\
Impurities & $\mathrm{ppm}$ & \\
$\quad \mathrm{Al}$ & & 125 \\
$\mathrm{Fe}$ & & 130 \\
$\mathrm{Ca}$ & $\mathrm{m}^{2} / \mathrm{s}$ & 150 \\
Specific surface area & $\mathrm{nm}$ & $40 \cdot 5$ \\
Equivalent particle size & & 37 \\
\hline
\end{tabular}




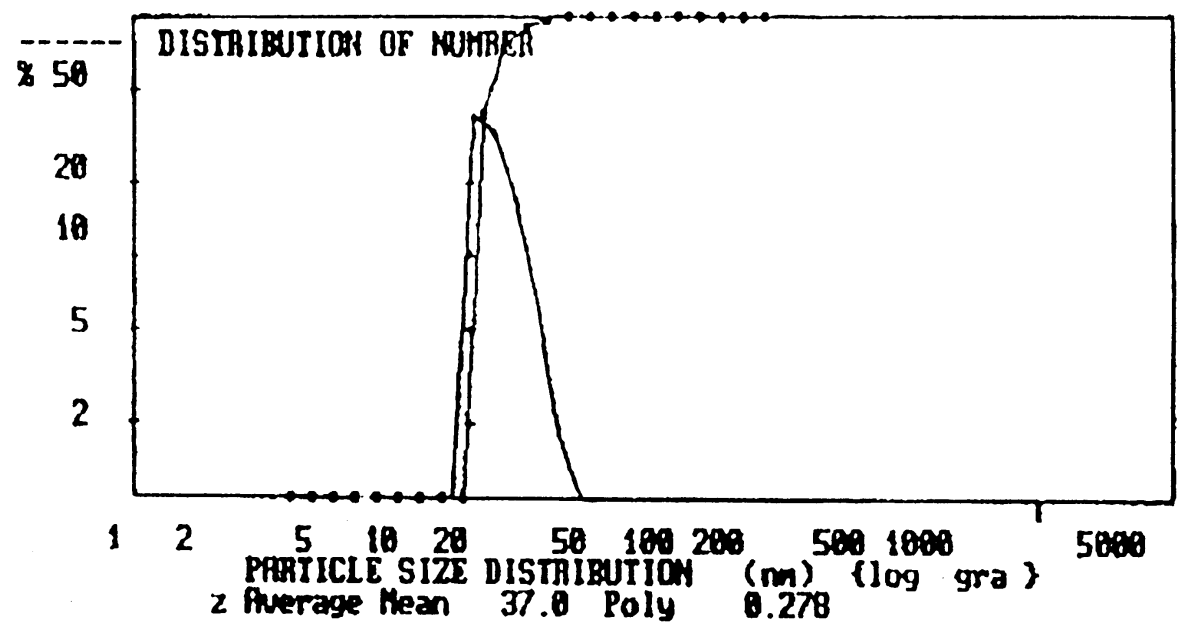

Figure 2. Particle size distribution of processed $\alpha$ silicon carbide powder.

\subsection{Sintering}

Sintering was carried out on bars of $50 \times 10 \times 20 \mathrm{~mm}$ and on pellets of size $10 \mathrm{~mm}$ in dia $\times 10 \mathrm{~mm}$ in thickness in an high temperature Astro furnace (Model No. 10003600-FP-20-F8204025 of M/s Thermal Technology Inc, USA) in the temperature range of $2000-2100^{\circ} \mathrm{C}$ for 15 min under vacuum (3 mbar).

\subsection{Sample preparation for TEM study}

For TEM study, cylindrical specimen of $3 \mathrm{~mm}$ diameter and $1 \mathrm{~mm}$ height, a size suitable for the fabrication of TEM specimens, was cut directly from the bulk sintered pellets of alpha silicon carbide. Specimens were prepared from these samples by mechanical thinning to $\cong 75 \mu \mathrm{m}$, followed by dimpling and subsequent low-energy ( 5 to $6 \mathrm{kV}$ ) and low angle $\left(15^{\circ}\right) \mathrm{Ar}^{+}$ion beam milling. The films were examined in a transmission electron microscope (JEOL TEM 400CX, Jeol, Japan) operated at an accelerating voltage of $100 \mathrm{kV}$.

\section{Results and discussion}

Nano crystalline particles of $\alpha$-SiC have been obtained in this study during attrition grinding as evident from figures 2 and 3 .

The change in bulk density of sintered body as a function of boron carbide concentration was measured at different sintering temperatures. The results obtained are shown in figure 4 , where one can see that the maximum sintered density is obtained at $0.5 \mathrm{wt} \% \mathrm{~B}_{4} \mathrm{C}$ concentration at each temperature from 2000 to $2100^{\circ} \mathrm{C}$. These results were obtained at constant amount of carbon addition (1 wt $\%$ ). Above $0.5 \mathrm{wt} \% \quad \mathrm{~B}_{4} \mathrm{C}$ concentrations, density

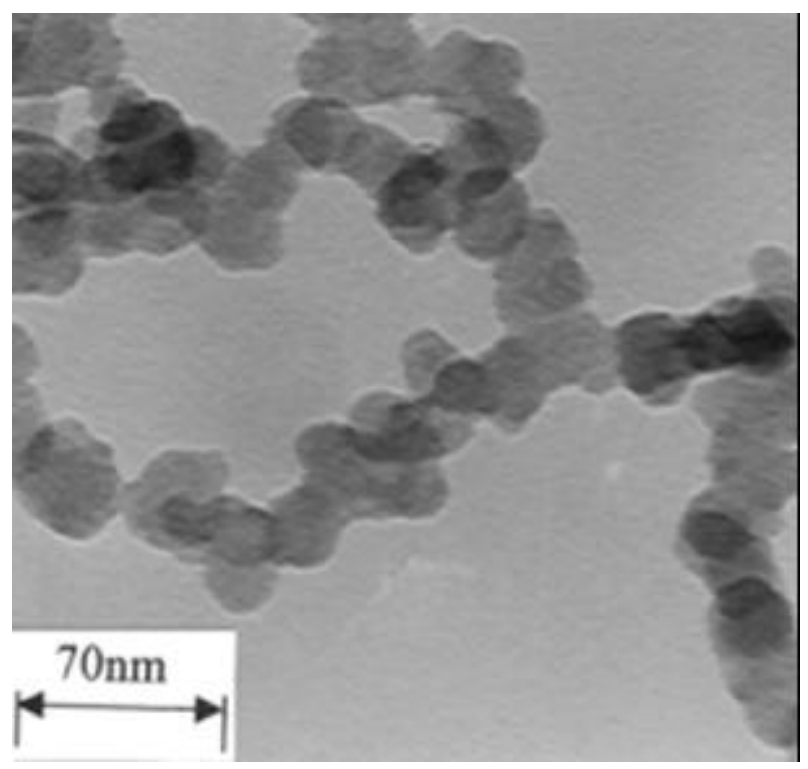

Figure 3. Transmission electron micrograph of processed $\alpha$ silicon carbide powder.

decreases from the peak value with increasing $\mathrm{B}_{4} \mathrm{C}$ concentration.

It is significant that sintered density changes from $62 \%$ theoretical density to $99 \%$ theoretical density at $0.5 \mathrm{wt} \%$ $\mathrm{B}_{4} \mathrm{C}$. This result suggests that the solid solubility of $\mathrm{B}_{4} \mathrm{C}$ in $\mathrm{SiC}$ may be $0.5 \mathrm{wt} \%$ in the temperature range $2000^{\circ}$ $\sim 2100^{\circ} \mathrm{C}$ as reported by Murata and Smoak (1978). As a matter of fact, the body having $99 \%$ T. D. exhibits a dense microstructure with relatively fine grains, the average size being $5 \mu \mathrm{m}$ measured on micrograph. Two types of porosities were identified in the microstructure, those between grain-boundaries and those within the bulk crystal. The latter were probably developed during grain growth of the original nano size silicon carbide grain. The needle like growth of grains of silicon carbide pointed out to the 
fact that the rate of crystallization from the original rather spherical particles produced by grinding and leaching etc has been very fast, favouring growth in a particular direction according to energy consideration. Due to growth from $37 \mathrm{~nm}$ to $5.7 \mu \mathrm{m}$ (figure 5), it is suggested that a group of grains after sintering should have the grain boundaries with relatively low energy.

To examine the effect of carbon on sintered density, experiments were carried out using compositions containing a constant amount of boron carbide $(0.5 \mathrm{wt} \%)$ and varied amounts of carbon (from zero to $5 \mathrm{wt} \%$ ).

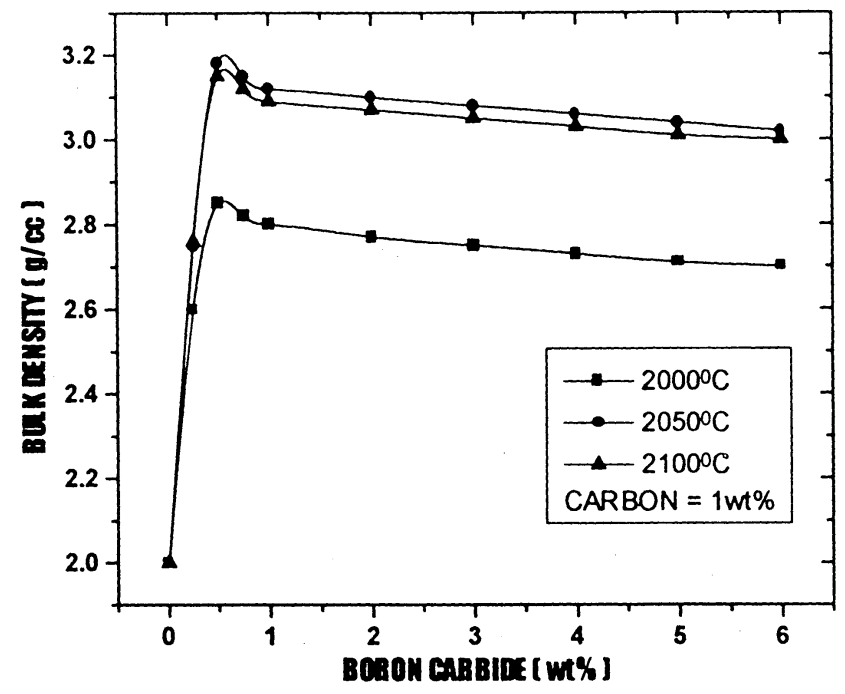

Figure 4. Sintered density vs boron carbide concentration at constant carbon content of $1 \mathrm{wt} \%$ at sintering time of $15 \mathrm{~min}$ in vacuum atmosphere (3 mbar).

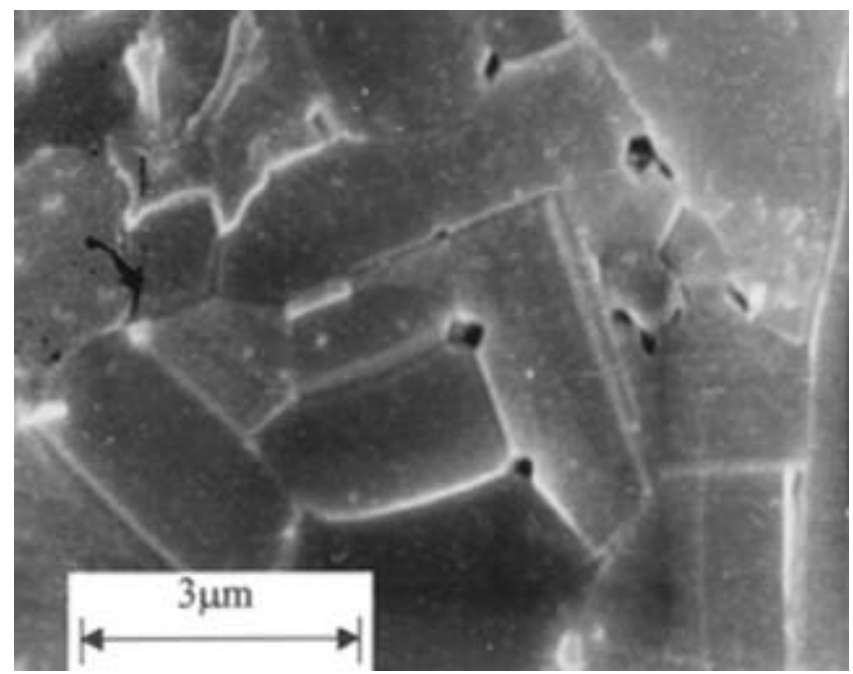

Figure 5. Microstructure of sintered $\alpha-\mathrm{SiC}\left(0.5 \mathrm{wt} \% \mathrm{~B}_{4} \mathrm{C}+\right.$ $1 \mathrm{wt} \% \mathrm{C}$ ) at a sintering temperature of $2050^{\circ} \mathrm{C}$ for $15 \mathrm{~min}$ in vacuum atmosphere (3 mbar).
In figure 6, the effect of carbon content on densification is shown in which the maximum density was obtained at $1 \mathrm{wt} \%$ carbon at each temperature from $2000^{\circ}$ $\sim 2100^{\circ} \mathrm{C}$. The curves shown in figure 6 also demonstrate that the addition of carbon was quite effective for enhancing the sintered density. For instance, at zero\% carbon, the sintered density is $2.15 \mathrm{~g} / \mathrm{cm}^{3}$, which is only an increase of $7.5 \%$ from green density of $2.0 \mathrm{~g} / \mathrm{cm}^{3}$. The density increases almost linearly with increasing carbon content up to $1 \mathrm{wt} \%$ and above $1 \mathrm{wt} \%$, it becomes almost saturated. Thus the role of carbon during sintering of silicon carbide has an very important effect. Silicon carbide always contains very small percentage of oxygen which is present as a very thin layer of native silica which is usually present on the surface of silicon carbide powder particles (Prochazka 1975; Hamminger et al 1983). A detrimental side reaction can take place in which the silica layer is reduced by the silicon carbide itself by the reaction

$$
2 \mathrm{SiO}_{2}+\mathrm{SiC} \rightarrow 3 \mathrm{SiO}+\mathrm{CO},
$$

for which $\Delta G=0$ at $1870^{\circ} \mathrm{C}$.

This volatile $\mathrm{SiO}$ is further reduced at higher temperature through the reaction

$$
\mathrm{SiC}+\mathrm{SiO} \rightarrow 2 \mathrm{Si}+\mathrm{CO} .
$$

This reaction with $\Delta G=0$ at $1950^{\circ} \mathrm{C}$ is very efficient at usual sintering temperatures $\left(2050^{\circ} \sim 2150^{\circ} \mathrm{C}\right)$. Thus silicon vapour is usually present at sintering temperatures when carbon is not added.

It is known (Raghavan 1974) that the equilibrium concentration of point imperfections i.e. vacancies for schottky defect for the minimum free energy at a particular temperature is given by

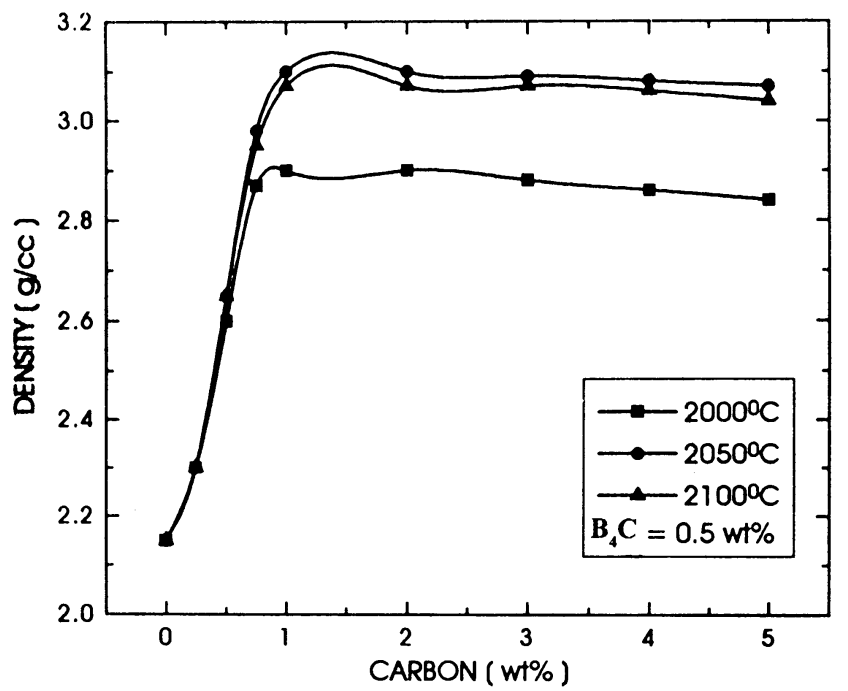

Figure 6. Sintered density vs carbon concentration at constant boron carbide content of $0.5 \mathrm{wt} \%$ at sintering time of $15 \mathrm{~min}$ in vacuum atmosphere (3 mbar). 


$$
n=N \exp \left(-\Delta H_{\mathrm{f}} / k T\right),
$$

where $N$ is number of sites and $n$ the number of vacancies.

Silicon carbide is a covalent compound. Thus carbon vacancies and silicon vacancies can be represented by

$$
\begin{aligned}
& n_{\mathrm{C}}=N \exp \left(-\Delta H_{\mathrm{c}} / k T\right), \\
& n_{\mathrm{Si}}=N \exp \left(-\Delta H_{\mathrm{Si}} / k T\right), \\
& n_{\mathrm{C}} \cdot n_{\mathrm{Si}}=N^{2} \exp \left[-\left(\Delta H_{\mathrm{f}}+\Delta H_{\mathrm{Si}}\right) / k T\right] .
\end{aligned}
$$

This product of $n_{\mathrm{C}} \cdot n_{\mathrm{Si}}$ is constant for a particular temperature.

Diffusion coefficient is simply the product of vacancy concentration, the jump frequency and one sixth the jump distance squared (Kingery et al 1975).

As there are 12 possible adjacent carbon and silicon sites, the diffusion coefficient of carbon and silicon can be represented by

$$
\begin{aligned}
& D_{\mathrm{Si}}=12\left[V_{\mathrm{Si}}\right] W_{0} \frac{\alpha^{2}}{6}, \\
& D_{\mathrm{C}}=12\left[V_{\mathrm{C}}\right] W_{0} \frac{\alpha^{2}}{6},
\end{aligned}
$$

where $W_{0}$ is the jump frequency and $\alpha$ the jump distance (Birnie and Dunbar 1986).

Thus the increase of diffusion coefficient of carbon will increase due to the increase of carbon vacancies and this will have to be followed by decrease of diffusion coefficient of silicon due to decrease of silicon vacancies and vice versa.

Chemical analyses of both pure $\beta$-silicon carbide and $\alpha-6 \mathrm{H}$ silicon carbide single crystal by three different laboratories have found the crystals to be silicon-rich. The ratio of silicon to carbon of $\beta-\mathrm{SiC}$ and $\alpha-6 \mathrm{H}$ were reported to be 1.049 and 1.032, respectively (Nagatomo et al 1979; Shaffer 1980). Thus the excess of silicon must result in carbon vacancies.

From (6), we can conclude that higher carbon vacancies with respect to silicon would result in higher diffusion coefficient of carbon with respect to that of silicon. This was exactly found by Hong et al (1979, 1980, 1981) who reported that carbon diffusion coefficient is two orders of magnitude larger than that of silicon in argon atmosphere (figure 7).

Also carbon and silicon vacancies are related to partial pressures of carbon and silicon. The higher carbon partial pressure would result in decrease in carbon vacancies, but promote an increase in silicon vacancies according to (6) as already explained.

An atmosphere rich in silicon would result in higher carbon vacancies, thereby showing an increase in carbon diffusion coefficient followed by a very high decrease in silicon diffusion coefficient. This was found by Hong et al (1979) (figure 8) who reported that carbon diffusion coefficient is three orders of magnitude larger than that of silicon and diffusion coefficient of silicon is also low.

This large discrepancy between diffusion coefficients of carbon and silicon in silicon rich atmosphere and generally the very low value of diffusion coefficient of both silicon and carbon prevent the sintering silicon carbide in silicon rich atmosphere at sintering range of $2050^{\circ} \sim 2150^{\circ} \mathrm{C}$ of silicon carbide which was discussed earlier.

The addition of carbon in well distributed manner reduces the native silica film layer on the surfaces of the silicon carbide particles by the overall reaction

$$
\mathrm{SiO}_{2}+3 \mathrm{C} \rightarrow \mathrm{SiC}+2 \mathrm{CO},
$$

for which the Gibbs free energy change $(\Delta G)$ is zero at $1520^{\circ} \mathrm{C}$.

Moreover, excess partial pressure of carbon decrease carbon vacancies thereby promoting silicon vacancies according to (6), increasing the diffusion coefficient of silicon, whereas decreasing that of carbon. It was also found by Ghostagore and Coble (1966) that silicon diffusion coefficient is higher than carbon diffusion coefficient at sintering temperature range of $2050^{\circ} \sim 2150^{\circ} \mathrm{C}$ of silicon carbide in carbon atmosphere. Therefore, the sintering behaviour of silicon carbide is different depending on silicon rich or carbon rich atmosphere due to the role of diffusion coefficients.

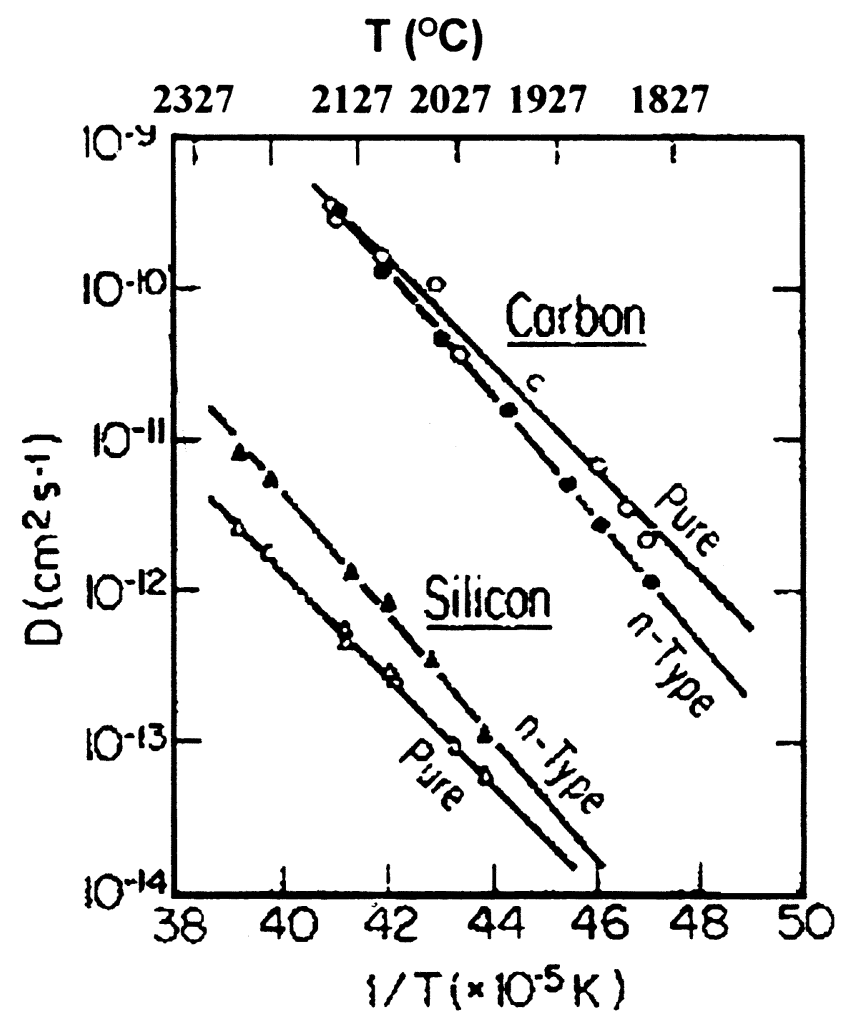

Figure 7. Carbon and silicon self-diffusion rates in silicon carbide single crystals. 
It was found that highest sintered densities were obtained when carbon percentage was $1 \mathrm{wt} \%$. The oxygen content of our processed powder was $0.33 \mathrm{wt} \%$. This oxygen remained as silica on the surface of the processed powder. Most of carbon was utilized to remove the surface silica according to (9) and the rest of carbon created a low partial pressure of carbon which was suitable enough to increase the diffusion coefficient of silicon. It was found by Hojo et al (1993) that highest sintered density was achieved when the amount of carbon added was just enough to completely remove the surface silica. Therefore, it can be concluded that the addition of $1 \mathrm{wt} \%$ of carbon is required for not allowing the formation of silicon atmosphere, which is normally present when carbon is not added according to the reactions (1) and (2), and which hinder the densification process as stated earlier. Also it forms an atmosphere of neutral to very low partial pressure of carbon, and hence enhances densification by increasing the diffusion coefficient of silicon, which is very low in silicon rich atmosphere (figure 8). The addition of excess carbon increases the

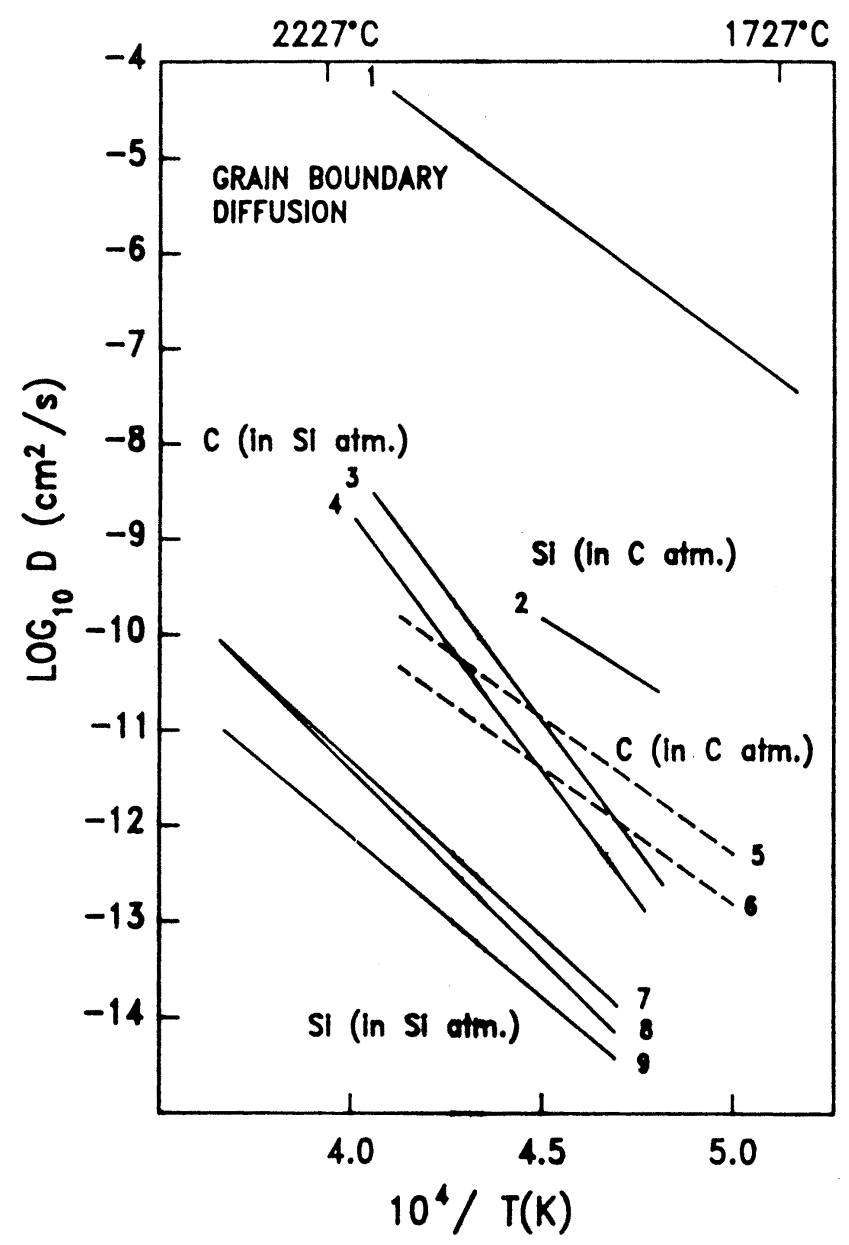

Figure 8. SiC self-diffusion in various atmospheres. Line 1 is grain-boundary diffusion of a polycrystalline sample. All other lines correspond with bulk diffusion in $\alpha$-SiC (lines 2, 4, 5, 6 and 8 ) or in $\beta$-SiC (lines 3 and 7 ). partial pressure of carbon. As carbon vacancies are inversely related to the partial pressure of carbon, therefore, the number of carbon vacancies would decrease thereby decreasing the diffusion coefficient of carbon resulting in the decrease of sintering rate.

It was found by Suzuky and Hase (1978) that the grain growth also became very prominent above $1900^{\circ} \mathrm{C}$. The observed structure development could be described as larger grains dissolving the surrounding smaller grains, and the mass of dissolving grains engulfing the pores located at the surface of grains. Thus, when the sintering rate decreases due to decrease in diffusion coefficient of carbon in presence of excess carbon partial pressure, the exaggerated grain growth which is very prominent at this sintering temperature becomes operative at a very fast rate compared to the sintering rate causing entrapment of the pores and thereby causing a decrease in the sintered density.

Through transmission electron microscopic study, no intergranular phase was observed at the grain-boundary, as shown in figure 9. It has been found from the electron diffraction pattern (figure 10) that boron has entered into solid solution with the silicon carbide. In order to examine the effect of boron, we studied the transmission electron microscopy of sample containing boron carbide of $3 \mathrm{wt} \%$ with $1 \mathrm{wt} \%$ of carbon sintered at $2050^{\circ} \mathrm{C}$ under vacuum ( 3 mbar). We found from electron micrograph (figure 11) that although sintered silicon carbide contained boron in its structure, excess boron carbide remained as separate phase, but not in the grain boundary. Therefore, we can conclude that sintering process of silicon carbide through boron carbide doping is a solid-state one.

We propose the following mechanism for enhancement of diffusion

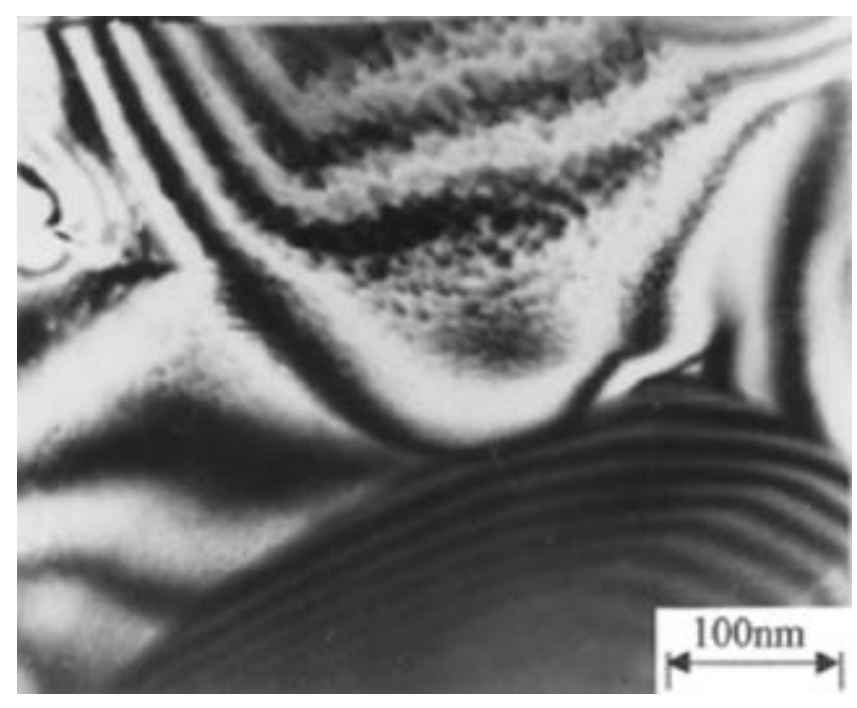

Figure 9. Transmission electron micrograph of $\alpha$ silicon carbide having boron carbide content of $0.5 \mathrm{wt} \%$ and carbon content of $1 \mathrm{wt} \%$ sintered at $2050^{\circ} \mathrm{C}$ for $15 \mathrm{~min}$ at vacuum (3 mbar). 


$$
\begin{aligned}
& \mathrm{SiC} \rightarrow \mathrm{Si}+\mathrm{C} \\
& \mathrm{B}_{4} \mathrm{C} \stackrel{\mathrm{SiC}}{\longrightarrow} 4 \mathrm{~B}_{\mathrm{Si}}^{\prime}+\mathrm{C}^{\prime \prime \prime \prime}+3 \mathrm{~V}_{\mathrm{C}} \\
& \mathrm{SiB}_{4} \stackrel{\mathrm{SiC}}{\longrightarrow} \mathrm{Si}^{\prime \prime \prime \prime}+4 \mathrm{~B}^{\prime}+3 \mathrm{~V}_{\mathrm{Si}}
\end{aligned}
$$

When boron enters into $\mathrm{C}$ site, $\mathrm{SiB}_{4}$ is likely to form. Thus silicon vacancies are created. Whereas when boron enters into $\mathrm{Si}$ site, $\mathrm{B}_{4} \mathrm{C}$ is likely to form. Thus carbon vacancies are created. The difference between covalent radius of $\mathrm{B}$ and $\mathrm{C}$ is $0 \cdot 11 \AA$ (lattice parameter measured by Murata and Smoak (1978) as reported earlier). The difference between $\mathrm{B}$ and $\mathrm{Si}$ covalent radius is $0.29 \AA$. The amount of $\mathrm{C}$ and $\mathrm{Si}$ replaced is calculated from the change in lattice parameter "c" and these are $71.85 \%$ and $28.15 \%$. Thus $\mathrm{SiB}_{4}$ is likely to be formed 2.55 times more than $\mathrm{B}_{4} \mathrm{C}$ formed. Thus silicon vacancy forms 2.55 times more than carbon vacancies. Thus diffusion coefficient of silicon increases more than twice the diffusion coefficient of carbon. Further, enhancement of silicon diffusion coefficient occurs due to carbon rich atmosphere. In argon atmosphere carbon diffusion coefficient is two orders of magnitude larger than that of silicon. But in carbon rich atmosphere, carbon diffusion coefficient is less than the diffusion coefficient of silicon and also enhancement of diffusion coefficient of silicon occurs as reported by Rijswijk and Shanefield (1990). Here carbon also prevents the formation of $\mathrm{B}_{4} \mathrm{C}$ structure and also decrease the vacancies of carbon. Thus it lowers the diffusion coefficient of carbon. The excess silicon must have resulted from carbon vacancies. It is found that selfdiffusion rate of each element is enhanced by the presence of other elements, because of the generation of vacancies. Thus, carbon atmosphere would equalize the ratio of $\mathrm{Si}$ to $\mathrm{C}$ to unity or less than unity in silicon

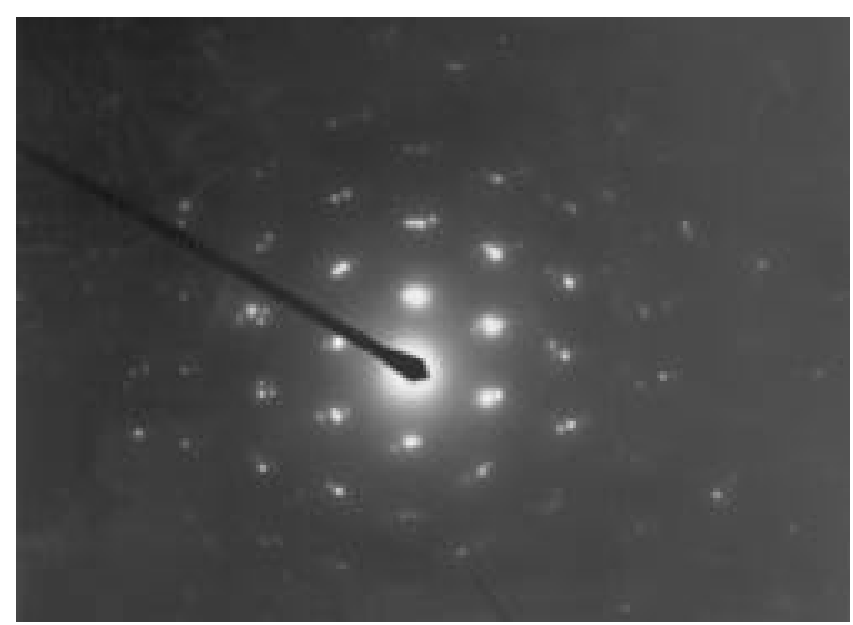

Figure 10. Electron diffraction pattern of $\alpha$ silicon carbide having boron content of $0.5 \mathrm{wt} \%$ and carbon content of $1 \mathrm{wt} \%$ sintered at $2050^{\circ} \mathrm{C}$ for $15 \mathrm{~min}$ at vacuum ( $3 \mathrm{mbar}$ ). carbide thereby creating silicon vacancies and thus increasing bulk diffusion of silicon. Addition of boron in silicon carbide creates further vacancies of silicon and carbon which enhance the bulk diffusion. If atom is associated with a vacancy, it always has an adjacent site to jump into such that atomic diffusion coefficient is similar to vacancy diffusion rather than the lattice diffusion, i.e. increased by many orders of magnitude (Kingery et al 1975). By this process addition of boron creates bulk diffusion of silicon and carbon increases by many orders of magnitude and become equal to grain boundary diffusion coefficient of both silicon and carbon vacancies. For densification to occur, the mass transport of silicon and carbon should be equal. Without addition of boron carbide and carbon, the mass transport of silicon and carbon are not equal and also low and densification does not occur. Whereas addition of boron carbide increases the diffusion coefficient and the carbon creates partial carbon atmosphere which makes the mass transport of silicon and carbon to enable densification to occur. It was found that the maximum density of silicon carbide has been obtained with addition of $0.5 \mathrm{wt} \%$ of $\mathrm{B}_{4} \mathrm{C}$. This was also found by Murata and Smoak (1978) who correlated this percentage of $\mathrm{B}_{4} \mathrm{C}$ as solubility limit of boron carbide from lattice parameter measurement which showed a sharp drop in lattice parameter up to $0.5 \mathrm{wt} \%$ of boron carbide addition to silicon carbide. After that, with further addition of boron carbide to silicon carbide, a slow decrease in lattice parameter was observed by them. Thus it can be interpreted that a part of boron carbide, added in excess, under non equilibrium conditions, entered into the structure of silicon carbide occupying vacant silicon and carbon sites thereby decreasing diffusion coefficients of silicon and carbon which were earlier enhanced by addition of boron carbide up to $0.5 \mathrm{wt} \%$. The other part

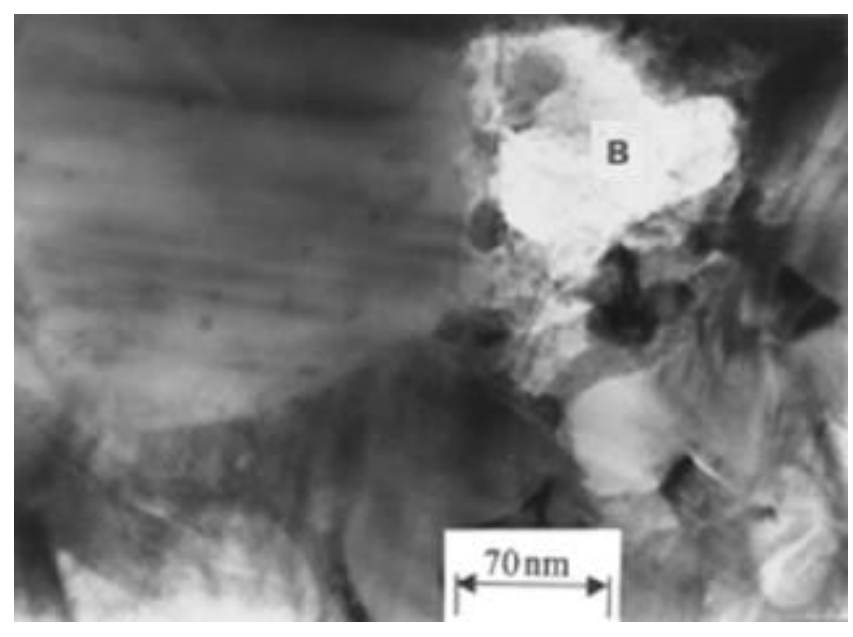

Figure 11. Transmission electron micrograph of $\alpha$ silicon carbide having boron carbide content of $3 \mathrm{wt} \%$ and carbon content of $1 \mathrm{wt} \%$ sintered at $2050^{\circ} \mathrm{C}$ for $15 \mathrm{~min}$ at vacuum (3 mbar). 
remained as separate phase. The decrease in diffusion coefficients of silicon and carbon make the sintering rate to be slow with increase of boron carbide addition above $0.5 \mathrm{wt} \%$. As stated earlier, the exaggerated grain growth which is very prominent at this sintering temperature, grows at a much faster rate than the sintering rate, engulfing the pores causing entrapment of pores thereby causing a decrease in sintered density.

Neither any segregation of boron carbide at the grain boundary region has been found in the grain boundary as stated by Prochazka (1975) in his hypothesis to explain the role of boron in the sintering of silicon carbide nor any liquid phase has been found to exist at the grain boundary region as stated by Lange and Gupta (1976). Therefore, on the basis of above discussion, we can conclude that sintering of silicon carbide by addition of boron carbide and carbon is solid state sintering process through vacancy creation and solid state diffusion process.

Formation of $\mathrm{SiB}_{4}$ increases the cell dimension whereas formation of $\mathrm{B}_{4} \mathrm{C}$ decreases the cell dimension. During sintering, the structure of $\mathrm{SiB}_{4}$ and $\mathrm{B}_{4} \mathrm{C}$ may begin to coalesce in different cells in layer displacement mechanism. The cells are likely to become disordered and strained. The cells containing $\mathrm{SiB}_{4}$ structure began to recrystallize as $4 \mathrm{H}$ polytype whereas the cell containing $\mathrm{B}_{4} \mathrm{C}$ began to precipitate from cell containing $\mathrm{B}_{4} \mathrm{C}$ structure. This may well be the reason for obtaining $71 \% 4 \mathrm{H}$ polytype from grains containing mainly $6 \mathrm{H}$ polytype. The quantitative measurement of silicon carbide polytypes from X-ray diffraction peak intensities developed by Ruska et al (1979) has been utilized.

The polytype transformation from $6 \mathrm{H}$ to $4 \mathrm{H}$ might result from suitable layer displacements caused by the

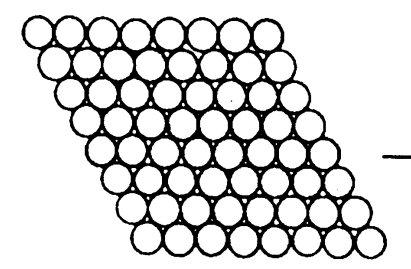

(a)

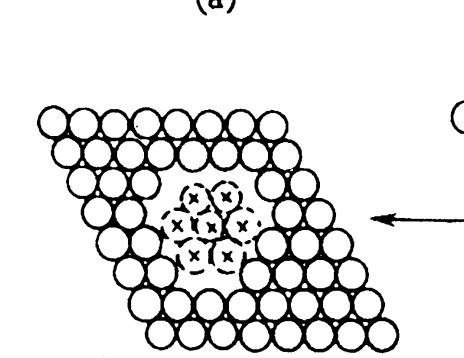

(d)

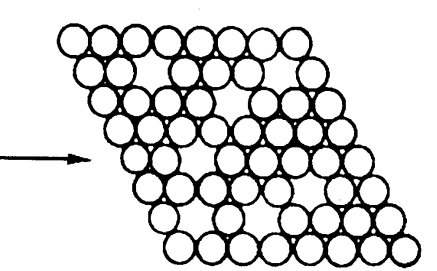

(b)

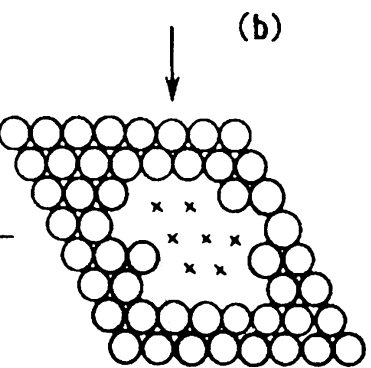

(c)
Figure 12. Nucleation of a stacking fault in a close-packed layer by thermal diffusion. Crosses $(x)$ indicate sites for atoms in the faulted layer. A partial dislocation surrounds the faulted region. nucleation and expansion of stacking faults in individual close-packed double-layers of $\mathrm{Si}$ and $\mathrm{C}$. This process is governed by thermal diffusion such as grain boundary diffusion since the nucleation of a stacking fault would require the migration of atoms inside the crystal. This layer displacement is likely to occur in such a manner as to minimize the free energy and take the structure towards the more stable one. If the stable state happens to be one with a different order such an order will tend to result. Such a mechanism was also suggested by Verma and Krishna (1966). During sintering by addition of $\mathrm{B}_{4} \mathrm{C}$ and carbon and the increase of temperature, vacancies would be created and atoms would become free to migrate within the crystal and to the surface by diffusion. If number of vacancies come closer together, it will become possible for neighbouring atoms to move into " $\mathrm{B}$ " sites thereby nucleating a fault. Within the region the atoms are in " $B$ " sites while the rest of atoms are in 'A' sites causing a partial dislocation to bound the fault. This partial dislocation glides causing the fault to expand until the entire layer of atoms is displaced into ' $\mathrm{B}$ ' sites and the partial dislocation moves out of the crystal. The entire layer is then displaced from ' $\mathrm{A}$ ' to ' $\mathrm{B}$ ' orientation (figure 12). By the same mechanism displacements occur for other layers throughout the structure in such a manner as to result in a new structure. By this mechanism transformation would proceed through one dimension disorder caused by the nucleation of stacking faults and is expected to exhibit considerable one-dimension disorder as observed by the needle-like crystals of $4 \mathrm{H}$ polytype. The growth of these needle-like crystals in later stage may also be governed by screw dislocation which was generated from the strains in the crystal structure due to incorporation of boron atom in the crystal.

\section{Conclusions}

(I) The maximum density of sintered $\alpha$-silicon carbide was obtained at the concentration of $0.5 \mathrm{wt} \%$ of boron carbide with $1 \mathrm{wt} \%$ of carbon at $2050^{\circ} \mathrm{C}$ for 15 min under vacuum (3 mbar).

(II) Boron carbide creates vacancies which enhance both $\mathrm{Si}$ and $\mathrm{C}$ diffusion coefficients by many orders of magnitude and make them equal to the grain boundary diffusion coefficient.

(III) Carbon reduces silica layer and enhance the bulk self diffusion coefficient of silicon carbide by many orders of magnitude. It also inhibit grain growth of $\mathrm{SiC}$ crystals. The optimum carbon content which gives rise to a high density was found to be $1 \mathrm{wt} \%$.

(IV) From the study of the transmission electron microscopy, the sintering process was found to be diffusion controlled solid-state sintering.

(V) $6 \mathrm{H}$ to $4 \mathrm{H}$ polytype transformation resulted from suitable layer displacement caused by nucleation and expansion of stacking fault. 


\section{References}

Birnie III and Dunbar P 1986 J. Am. Ceram. Soc. 69 C33

Ghostagore R N and Coble R L 1966 Phys. Rev. 143623

Hamminger R, Grathwohj G and Thummler F 1983 J. Mater. Sci. 18353

Hong J D and Davis R F 1980 J. Am. Ceram. Soc. 63546

Hong J D, Hon M H and Davis R F 1979 Ceram. Int. 5155

Hong J D, Hon M H and Davis R F 1980 in Materials science monographs (New York: American Elsevier) p. 409

Hong J D, Davis R F and Newbury D E 1981 J. Mater. Sci. 16 2485

Hojo J, Miyachi K, Okabe Y and Kato A 1983 J. Am. Ceram. Soc. $7 \mathrm{C} 114$

Kingery W D, Bowen H K and Uhlmann D R 1975 Introduction to ceramics (New York: John Wiley and Sons, Inc.) p. 223 \& p. 234

Kriegesman J, Hunold K, Lipp A, Reinmuth K and Schwetz K 1986 US Patent 4564601

Lange F and Gupta T K 1976 J. Am. Ceram. Soc. 59557

Murata Y and Smoak R H 1978 Proc. of int. symp. of factors in densification and sintering of oxide and non-oxide ceramics (Japan: Hakone) p. 382

Nagatomo M, Ishiwara H and Furukawa S 1979 Jpn. J. Appl. Phys. 18765

Prochazka S 1975 in Special ceramics (New York: Academic Press) Vol. 6, p. 171

Raghavan V 1974 First course in material science (New Delhi: Prentice-Hall of India Pvt Ltd) p. 68

Rijswijk W Van and Shanefield J Daniel 1990 J. Am. Ceram. Soc. 73148

Ruska J, Gauckler L J, Lorenz J and Rexer H U 1979 J. Mater. Sci. 142013

Shaffer P T B 1969 Mater. Res. Bull. S4 97

Shaffer P T B 1980 Mater. Res. Bull. 16699

Suzuki H and Hase T 1978 Proc. of int. symp. of factors in densification and sintering of oxide and non-oxide ceramics (Japan: Hakone) p. 345

Tajima Y and Kingery W D 1982 J. Am. Ceram. Soc. 65 C33

Verma A R and Krishna P 1966 in Polymorphism and polytypism in crystal (New York: John Wiley and Sons, Inc.) p. 261 